Conclusion The study will quantify the risk of patient safety incidents among ethnic minority patients in hospital care, unravel the causes, and identify policy opportunities to minimise inequities in care.

\section{P1-367 ADOLESCENT'S ORAL HEALTH: ODONTOLOGICAL NEEDS RAISED BY COMMUNITY HEALTH AGENTS}

doi:10.1136/jech.2011.142976f.59

${ }^{1} \mathrm{M}$ V de Lima Saintrain, * ${ }^{1} \mathrm{C}$ R S Correa, ${ }^{1}$ A P G F Vieira. ${ }^{1}$ Universidade de Fortaleza, Fortaleza, Ceará, Brazil; ${ }^{2}$ Universidade de Campinas, Campinas, São paulo, Brazil

Introduction Epidemiological data are essential for the development of public policies aiming at health promotion and prevention of risk situations, including those that compromise oral health.

Objective To present epidemiological data on adolescents' oral health collected by community health agents (CHA) utilising the Oral Health Community Indicator (ICSB).

Methodology Cross-sectional study conducted in Guaiúba-CE from July 2007 to February 2008. After calibration and training by community health agents, using the ICSB, a total of 743 adolescents were examined. The study was approved by the University of Fortaleza Research Ethics Committee (No. 001/2007).

Results The adolescents had an average of 26.14 \pm 3.61 teeth, 129 $(17.4 \%)$ did not present caries, $301(40.5 \%)$ had one or two, 223 (30.0\%), three or more, 110 (14.8\%) presented residual root, 121 $(25.7 \%)$ tatar, $74(10.0 \%)$ sore gingiva, $15(2.0 \%)$ oral tissues injuries, $49(6.6 \%)$ required prosthesis, 694 (93.4\%) used toothbrush, and 281 $(51.3 \%)$ visited the dentist last year. It was detected an association between the variables: visit to the dentist in the past year $(p=0.0001)$ and gender and between age below 12 and having three or more caries $(\mathrm{p}=0.023)$.

Conclusion The CHA was able to collect relevant data to the elaboration of public policies aiming equity. The assessed adolescents did not reach the goal set by the International Dental Federation, which is, on average, one decayed, missing or filled tooth.

\section{P1-368 PHYSICAL ACTIVITY AND ENVIRONMENT PERCEPTION IN ELDERLY: POPULATION STUDY IN SOUTHERN BRASIL}

doi:10.1136/jech.2011.142976f.60

M W Corseuil, ${ }^{*}$ I J C Schneider, E d'Orsi. Federal University of Santa Catarina, Florianópolis, Santa Catarina, Brazil

Introduction The aim of this study was to evaluate the association between perceived environment and leisure-time physical activity level in a population sample of elderly in a southern capital of Brazil. Methods Cross-sectional study included 1656 elderly (60 years and older) living in the urban area of Florianopolis, Santa Catarina, Brazil in 2009-2010. The leisure-time physical activity was measured using the long International Physical Activity Questionnaire. The 150 min time limit of physical activity per week was used to classify individuals who were active during leisure time. Environmental variables were assessed using a modified version of the Neighbourhood Environment Walkability Scale. Poisson' regression analysis was used to examine the association of environment variables with leisure-time physical activity with calculated prevalence ratios and CIs of $95 \%$ and $p$ values (Wald test) (STATA 9). The analysis took into consideration the clustering of each sample.

Results The prevalence of leisure-time physical activity was $29.7 \%$ (95\% CI 26.0 to 33.3), 35.6\% (95\% CI 29.7 to 41.6) among men and $26.3 \%$ (95\% CI 23.1 to 29.4 ) in women. The existence of sidewalks, bikeways, pedestrian paths, social support from friends/neighbours to motivate physical activities and climate were parameters independently associated with leisure time physical activity.

Conclusion The results suggest that the construction of a safe and enjoyable public environment inside populated urban areas stimulates physical activity practices and thus should be considered Social network can develop and encourage leisure-time physical activities in the society nearby which is especially important for elderly population.

\section{P1-369 THE ASSOCIATION BETWEEN ORAL CONTRACEPTIVE USE AND BONE MASS IN BOTH YOUNG AND OLDER WOMEN}

doi:10.1136/jech.2011.142976f.61

S Wei, ${ }^{*}$ A venn, G Jones. Menzies Research Institute, University of Tasmania, Hobart, Tasmania, Australia

Introduction The association between oral contraceptive use and bone mass remains inconclusive.

Aim To describe the associations between current and ever use of $\mathrm{OC}$, bone mass and vertebral deformity in population-based samples of women.

Methods Data were collected from women aged 26-36 years ( $n=687$ ) in the Childhood Determinants of Adult Health study and aged $50-80$ years $(n=491)$ in the Tasmanian Older Adult Cohort study. OC use was assessed by questionnaire. Bone mass and vertebral deformity were measured by either quantitative ultrasound or dual-energy x-ray absorptiometry.

Analysis Multivariable linear regression analysis was employed to examine the associations between $\mathrm{OC}$ use and bone mass with adjustment for confounders. Logistic regression analysis was used to investigate the associations between $\mathrm{OC}$ use and the presence of vertebral deformity.

Results In young women, current OC use was associated with higher broadband ultrasound attenuation (BUA, $\beta=0.21$ ), speed of sound (SOS, $\beta=0.23$ ) and quantitative ultrasound index (QUI, $\beta=0.23$ ) (all, $p<0.05$ ). The associations remained significant after adjustment except for SOS. In older women, ever use of OC was associated with a higher $\mathrm{BMD}$ at the total body $(6 \%, \mathrm{p}<0.001)$ and spine $(4 \%, p=0.05)$ after adjustment. Longer duration of use was also associated with total body and spine BMD. Consistent reductions in vertebral deformity were observed but these only reached significance for 5 to 10 years use (adjusted OR 0.46, 95\% CI 0.22 to 0.94).

Conclusion OC use is consistently associated with higher bone mass in both young and older women in these population-based samples.

\section{P1-370 LESSONS FOR ZOONOTIC DISEASE AND VECTOR ERADICATION IN NEW ZEALAND FROM PAST SUCCESSES}

doi:10.1136/jech.2011.142976f.62

${ }^{1} \mathrm{~N}$ Wilson, ${ }^{*} \mathrm{D}$ Lush, ${ }^{3} \mathrm{P}$ Bell. ${ }^{1}$ University of Otago, Wellington, New Zealand; ${ }^{2} \mathrm{MAF}$ Biosecurity New Zealand, Wellington, New Zealand; ${ }^{3}$ Department of Conservation, Wellington, New Zealand

Introduction Regional and global disease eradication remains attractive for epidemiologists and policy makers (Science 2010;330:1736-9). New Zealand has successfully eradicated endemic brucellosis and hydatids. It recently eradicated the southern saltmarsh mosquito (SSM), Aedes camptorhynchus, a vector for Ross River virus. In some areas of the country bovine tuberculosis appears to have been eliminated via various control measures relating to the brushtail possum (Trichosurus vulpecula). 